\title{
SPARC is a possible predictive marker for albumin-bound paclitaxel in non-small-cell lung cancer
}

\author{
Kazutoshi Komiya' \\ Tomomi Nakamura' \\ Chiho Nakashima' \\ Koichiro Takahashi' \\ Hitomi Umeguchi',2 \\ Naomi Watanabe' \\ Akemi Sato' \\ Yuji Takeda' ${ }^{1,3}$ \\ Shinya Kimura' \\ Naoko Sueoka-Aragane \\ 'Department of Internal Medicine, \\ Division of Hematology, Respiratory \\ Medicine and Oncology, Faculty of \\ Medicine, Saga University, ${ }^{2}$ Japanese \\ Red Cross Karatsu Hospital, \\ ${ }^{3}$ Department of Thoracic Surgery, \\ Faculty of Medicine, Saga University, \\ Saga, Japan
}

This article was published in the following Dove Press journal:

OncoTargets and Therapy

27 October 2016

Number of times this article has been viewed

Objectives: Nanoparticle albumin-bound paclitaxel (nab-paclitaxel) produced good tumor response in cases with lung squamous cell carcinoma, one of the most difficult cancers to treat. Secreted protein acidic and rich in cysteine (SPARC) binds to albumin, suggesting that SPARC plays an important role in tumor uptake of nab-paclitaxel. There is as yet no predictive marker for cytotoxic agents against non-small-cell lung cancer (NSCLC), and hence we believed that SPARC expression might be associated with tumor response to nab-paclitaxel.

Patients and methods: We studied stromal SPARC reactivity and its association with clinicopathological characteristics in 200 cases of NSCLC using a custom tissue microarray fabricated in our laboratory by immunohistochemical staining. We also investigated the relationship between stromal SPARC reactivity and tumor response to nab-paclitaxel using biopsy or surgical specimens obtained from advanced or recurrent lung cancer patients.

Results: High SPARC stromal reactivity ( $>50 \%$ of optical fields examined) was detected in $16.5 \%$ of cases and intermediate SPARC reactivity $(10 \%-50 \%)$ in $56 \%$ of cases. High expression in cancer cells was rare (five cases). Stromal SPARC level was correlated with smoking index, squamous cell carcinoma, and vessel invasion. Furthermore, patients with high stromal SPARC reactivity in biopsy specimens such as transbronchial lung biopsy or surgical specimens tended to respond better to nab-paclitaxel.

Conclusion: Stromal SPARC was detected by immunohistochemical staining in $\sim 70 \%$ of NSCLC cases, and good tumor response to nab-paclitaxel was correlated with high stromal SPARC reactivity. SPARC may be a useful predictive marker for selecting patients likely to respond favorably to nab-paclitaxel treatment.

Keywords: lung cancer, nab-paclitaxel, SPARC, predictive marker, squamous cell carcinoma

\section{Introduction}

Chemotherapy continues to occupy a leading role in the treatment of advanced and recurrent non-small-cell lung cancer (NSCLC), whereas most new chemotherapeutic agents and molecular targeted therapy are for lung adenocarcinoma. EGFR activating mutations or $E M L 4-A L K$ fusion genes are established predictive markers in molecular targeted therapy. ${ }^{1,2}$ However, efficacy of anti-cancer agents for the treatment of lung squamous cell carcinoma is limited compared to adenocarcinoma, and molecular targeted therapy is not indicated for most patients with squamous cell carcinoma. Recently, Socinski et $\mathrm{al}^{3}$ reported that carboplatin plus nanoparticle albumin-bound paclitaxel (nab-paclitaxel) as a first-line therapy in patients with advanced NSCLC demonstrated a significantly higher overall response rate than carboplatin plus solventbased paclitaxel $(33 \%$ vs $25 \%, P=0.005)$ and in patients with squamous histology
Correspondence: Naoko Sueoka-Aragane Department of Internal Medicine, Division of Hematology, Respiratory Medicine and Oncology, Faculty of Medicine, Saga University, 5- I-I Nabeshima, Saga 849-850I, Japan $\mathrm{Tel}+8 \mathrm{I} 952342369$ Fax +8I 952342017 Email sueokan@cc.saga-u.ac.jp 
compared to patients with non-squamous histology (41\% vs $24 \%, P<0.001)$. An important property of nab-paclitaxel is an excellent tumor shrinkage effect, leading to relief from cancer-related symptoms. This antitumor effect is detected not only in squamous cell carcinoma but also in some patients with adenocarcinoma according to clinical observations. Based on these results, we thought that it would be useful to identify a predictive marker for nab-paclitaxel.

nab-Paclitaxel is a $130 \mathrm{~nm}$ albumin-bound formulation of paclitaxel particles (Celgene, Summit, NJ, USA). Albumin is the most abundant plasma protein, with a molecular weight of $66 \mathrm{kDa}$, and is emerging as a versatile carrier for targeted drug delivery. ${ }^{4}$ Secreted protein acidic and rich in cysteine (SPARC), also referred to as osteonectin or basement membrane protein 40 (BM-40), plays a crucial role in cell growth and angiogenesis through interaction with the extracellular matrix or cytokines. ${ }^{5-7}$ SPARC binds to albumin and the bound form co-localizes in cancer tissues, suggesting that SPARC plays an important role in promoting tumor uptake of nab-paclitaxel. ${ }^{8,9}$ Expression of SPARC is correlated with prognosis in breast cancer cases, ${ }^{10,11}$ and high SPARC stromal reactivity is correlated with improved survival in pancreatic cancer cases. ${ }^{12}$ However, there has been no investigation of the relationship between SPARC stromal reactivity and tumor response to nab-paclitaxel in NSCLCs. Lung squamous cell carcinoma, one of the most difficult cancers to treat, showed good tumor response to nab-paclitaxel. ${ }^{3}$ Although recent studies $^{1,2}$ have described predictive markers for molecular targeted therapy, there have been few reports of studies focusing on predictive markers for chemotherapeutic agents. Since nabpaclitaxel is produced by the albumin transportation system, SPARC bound to albumin may be a predictive marker. If SPARC is useful as a predictive marker in the clinical setting, we expect that patient selection based on SPARC expression could lead to a tailor-made therapy for lung cancer patients, especially those with squamous histology. In this study, we present evidence to support the possibility that SPARC may indeed be a predictive marker for nab-paclitaxel.

\section{Patients and methods}

\section{Tissue samples and tissue microarrays}

Tissue samples were surgical specimens obtained from 200 successive lung cancer patients who underwent surgery at Saga Medical School Hospital between 2004 and 2009 without anticancer chemotherapy or thoracic irradiation before surgery. The study was approval by the Saga University Clinical Research Ethics Committee; informed consent was obtained from all patients for the use of surgical specimens in this study. The tissue microarray was constructed using a Tissue Microarrayer (Pathology Institute Corp., Toyama, Japan). Two $1 \mathrm{~mm}$ diameter cylinders were punched from each of the 200 specimens and arrayed in three tissue microarray blocks. The clinical stage of the cancer was determined according to the criteria of the 7 th edition of the International Union Against Cancer.

\section{Immunohistochemical staining}

Deparaffinized $4 \mu \mathrm{m}$-thin tissue sections were microwaved in Tris-EDTA buffer ( $\mathrm{pH}$ 9.0). After blocking the tissue sections in $0.3 \%$ hydrogen peroxide in phosphate-buffered saline for 30 minutes at room temperature, serially cut sections were incubated overnight at $4^{\circ} \mathrm{C}$ with anti-SPARC antibody (Abcam, Cambridge, MA, USA) at 1:200 dilution, anti-CK7 antibody at 1:200, or anti-vimentin antibody at 1:200. The Dako EnVision System (DAKO Corp., Carpinteria, CA, USA) was used for detection. Counter staining was performed with hematoxylin. Immunohistochemical examination with each antibody was performed by the following criteria and scored according to sequential arbitrary cutoffs. Staining of the cancer cell nuclei or cytoplasm with anti-SPARC antibody in whole tissue sections was taken as positive and scored as $-(\leq 10 \%$ positive cells $), \pm(>10 \%$ but $\leq 30 \%),+(>30 \%$ but $\leq 60 \%)$, and $++(>60 \%)$. SPARC stromal reactivity was defined as the percentage of reactive stromal area among the optical fields and scored as $-(\leq 10 \%$, low $),+(>10 \%$ but $\leq 50 \%$, intermediate $)$, and $++(>50 \%$, high $)$. We defined positive staining as intermediate or high stromal reactivity. All slides were scored by three researchers.

\section{Treatment and assessment of efficacy}

Forty-three patients had histologically or cytologically confirmed advanced or recurrent NSCLC and were treated with $100 \mathrm{mg} / \mathrm{m}^{2} 30$-minute infusion of nab-paclitaxel on days 1,8 , and 15, with nab-paclitaxel followed by carboplatin AUC 6 on day 1 ; this regimen was repeated every 3 weeks. Treatment of at least six cycles is encouraged in general clinical practice, but can continue beyond six cycles in the absence of progressive disease if there is no unacceptable toxicity. Tumor response was evaluated according to Response Evaluation Criteria In Solid Tumors (RECIST) Version 1.1.

\section{Statistical analysis}

Associations between immunohistochemical staining results and clinicopathological characteristics were examined using the chi-square test for categorical data. The survival rate was calculated according to the Kaplan-Meier method, and 
the log-rank test was used for assessing differences. Cox proportional hazards regression analysis, with adjustment for potentially confounding variables gender, age, smoking index, and pathological stage, was used to calculate the mortality hazard rate (HR) and 95\% confidence interval (CI). $P$-values $<0.05$ were regarded as statistically significant. Statistical analyses were conducted using SPSS 11.0J (SPSS Japan Inc., Tokyo, Japan).

\section{Results}

\section{Expression of SPARC was correlated with smoking status, squamous cell carcinoma, vessel invasion, and poor prognosis in NSCLC patients}

Table 1 summarizes the relationships between SPARC stromal reactivity and clinicopathological characteristics based on the immunohistochemical analysis using antiSPARC antibody. A representative case of immunostaining

Table I Relationship between SPARC stromal reactivity and clinicopathological characteristics

\begin{tabular}{|c|c|c|c|c|}
\hline $\begin{array}{l}\text { SPARC stromal } \\
\text { reactivity }\end{array}$ & $<10 \%(-)$ & $10 \%-50 \%(+)$ & $>\mathbf{5 0} \%(++)$ & $P$-value \\
\hline Total $(\mathrm{N}=200)$ & 55 (27.5\%) & II 2 (56\%) & $33(16.5 \%)$ & \\
\hline Sex & & & & 0.08 \\
\hline Male $(n=\mid 16)$ & 25 & 69 & 22 & \\
\hline Female $(n=84)$ & 30 & 43 & 11 & \\
\hline $\mathrm{BI}$ & & & & 0.01 \\
\hline$<400(\mathrm{n}=102)$ & 37 & 53 & 12 & \\
\hline$\geq 400(n=98)$ & 18 & 59 & 21 & \\
\hline Histology & & & & $0.03^{\mathrm{a}}$ \\
\hline Ad $(n=\mid 55)$ & 48 & 86 & 21 & \\
\hline Sq $(n=29)$ & 3 & 18 & 8 & \\
\hline Other $(n=16)$ & 4 & 8 & 4 & \\
\hline p-stage & & & & 0.12 \\
\hline I $(n=144)$ & 44 & 78 & 22 & \\
\hline II $(n=30)$ & 7 & 14 & 9 & \\
\hline III $(n=18)$ & 2 & 14 & 2 & \\
\hline IV $(n=8)$ & 2 & 6 & 0 & \\
\hline EGFR mutation & & & & 0.13 \\
\hline $\begin{array}{l}\text { Ex19 or } e \times 21 \\
(n=73)\end{array}$ & 25 & 40 & 8 & \\
\hline $\begin{array}{l}\text { Not mutated } \\
(n=127)\end{array}$ & 30 & 72 & 25 & \\
\hline$V_{\text {essel invasion }}^{\mathrm{b}}$ & & & & 0.03 \\
\hline Positive $(n=53)$ & 8 & 32 & 13 & \\
\hline Negative $(n=\mid 40)$ & 45 & 76 & 19 & \\
\hline Lymphatic invasion ${ }^{\mathrm{b}}$ & & & & 0.23 \\
\hline Positive $(n=33)$ & 5 & 22 & 6 & \\
\hline Negative ( $n=159)$ & 47 & 86 & 26 & \\
\hline
\end{tabular}

Notes: ${ }^{a} \mathrm{Ad}$ vs Sq; ${ }^{\mathrm{b} E v a l u a b l e ~ c a s e s ~ o n l y . ~}$

Abbreviations: SPARC, secreted protein acidic and rich in cysteine; BI, Brinkman index; Ad, adenocarcinoma; Sq, squamous cell carcinoma. with anti-SPARC antibody is shown in Figure 1. Positive staining for SPARC (+ or ++) was detected in stromal fibroblasts and endothelial cells of immature vessels of the lung cancer tissues. In contrast, positive staining of cytoplasmic or nuclear SPARC in cancer cells was rare, noted in five of $200(2.5 \%)$ or 17 of $200(8.5 \%)$ cases examined, respectively. Staining level in the adjacent noncancerous tissue was low. One hundred and forty-five patients (72.5\%) showed positive staining for SPARC using immunohistochemistry. Immunostaining positivity was significantly higher in patients with Brinkman index $(\mathrm{BI}) \geq 400(80 / 98,82 \%)$ compared to those with $\mathrm{BI}<400(65 / 102,64 \%$; $P=0.01)$. Immunostaining positivity was higher in squamous cell carcinoma $(26 / 29$, $90 \%$ ) compared with adenocarcinoma (107/155, 69\%; $P=0.03)$ and was higher in vessel-invasion positive $(45 / 53$, $85 \%$ ) compared with vessel-invasion negative $(95 / 140,68 \%)$ cases $(P=0.03)$. Differences according to gender, pathological stage, EGFR mutation status, and lymphatic invasion were not statistically significant.

Because SPARC expression has been reported to be connected with poor prognosis in breast cancer, we investigated the prognosis associated with SPARC expression in patients with lung cancer. Table 2 shows that, based on the multivariate Cox proportional hazards model, pathological stage evidenced a significant effect on survival even with adjustment of one for the other. Stromal SPARC reactivity tended to be associated with poor survival, but the association was not statistically significant. Among the patients in stage I, those with positive staining for stromal SPARC had significantly shorter survival than negative staining (log-rank $P=0.05$, Figure 2$)$.

\section{Stromal SPARC reactivity is a possible predictive marker for nab-paclitaxel in advanced or metastatic NSCLC patients}

Table 3 shows the relationship between stromal SPARC reactivity in biopsy or surgical specimens from 43 lung cancer patients and tumor response to nab-paclitaxel in advanced or metastatic NSCLCs. Pretreatment biopsy specimens were obtained from nine transbronchial lung biopsies (TBLBs), three transbronchial biopsies (TBB), three computed tomography-guided lung biopsies, 13 endobronchial ultrasound-guided transbronchial needle aspirations (EBUS-TBNA), and 15 surgical specimens (12 primary lesions and three metastatic lesions). Tumor response evaluated according to RECIST Version 1.1 revealed that the best overall response to chemotherapy that could be achieved up to regression or recurrence was a partial response in 20 cases (47\%), stable disease in 13 cases $(30 \%)$, and progressive 


\section{A}

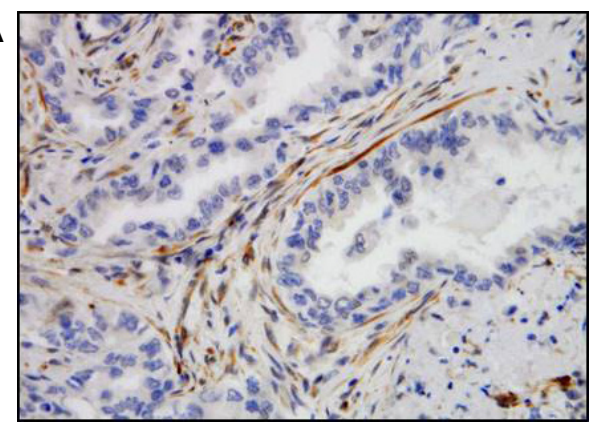

B

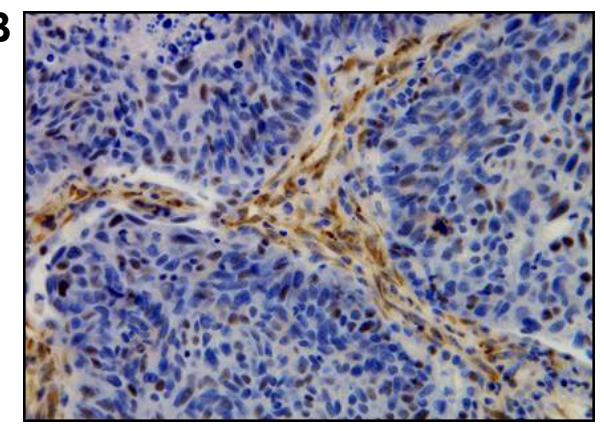

D

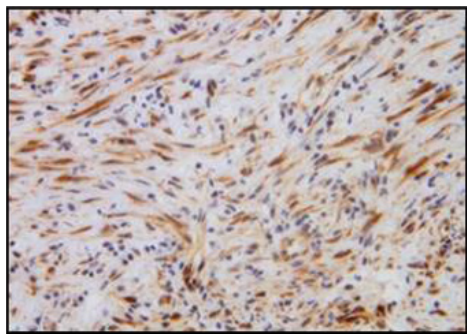

Figure I Expression of SPARC in lung cancer tissues.

Notes: Immunohistochemical staining of lung adenocarcinoma tissue was performed using anti-SPARC antibody $(\mathbf{A}, \times 400)$ and lung squamous cell carcinoma tissue (B, $\times 400)$. Counter staining was performed by hematoxylin. (C) (a) CT findings of the lung tumor in one case: a primary tumor was observed in the left lower lobe. The tumor position is indicated by the yellow arrows. After two cycles of chemotherapy, the tumor was markedly reduced (b). Immunohistochemical staining of TBLB samples from the primary lesion before treatment were performed using anti-SPARC antibody (D, $\times 400)$.

Abbreviations: SPARC, secreted protein acidic and rich in cysteine; CT, computed tomography; TBLB, transbronchial lung biopsy.

disease in 10 cases $(23 \%$; Table 4$)$. Stromal SPARC reactivity was $++(>50 \%)$ in 18 cases $(42 \%),+(10 \%-50 \%)$ in 11 cases $(25.5 \%),-(0 \%-10 \%)$ in five cases $(11.5 \%)$, and not evaluable in nine cases $(21 \%)$. Most nonevaluable cases had little tumor stroma in the biopsy specimens, which was often observed in EBUS-TBNA. Stromal SPARC reactivity was high (++) in almost all evaluable cases with partial response to nab-paclitaxel, intermediate (+) in seven of eleven of those with stable disease, and low (-) in three of eight of those with progressive disease, suggesting that stromal SPARC reactivity may be a predictive marker for nab-paclitaxel in NSCLC (Table 4). In particular, high stromal reactivity is a reliable marker for tumor shrinkage in response to nab-paclitaxel ( $P=0.002$ by Fisher's exact test). A representative case is

Table 2 Survival outcome by multivariate Cox proportional hazards analysis for NSCLC patients

\begin{tabular}{lll}
\hline Factors & $\begin{array}{l}\text { Hazard ratio } \\
(\mathbf{9 5 \%} \mathbf{C l})\end{array}$ & P-value \\
\hline Gender (male/female) & $2.45(0.76-7.95)$ & 0.14 \\
Age & $1.03(1.00-1.07)$ & 0.08 \\
Smoking index $(\geq 400 /<400)$ & $1.09(0.38-3.09)$ & 0.88 \\
Pathological stage & $3.75(1.89-7.42)$ & $<0.01$ \\
SPARC (positive/negative) & $1.58(0.65-3.85)$ & 0.31 \\
\hline
\end{tabular}

Abbreviations: $\mathrm{Cl}$; confidence interval; NSCLC, non-small-cell lung cancer; SPARC, secreted protein acidic and rich in cysteine. described as follows. Figure 1 shows a case of inoperable stage IIIA squamous cell carcinoma in a 70-year-old woman with smoking index 900. After two cycles of carboplatin plus nab-paclitaxel as a first-line chemotherapy, primary tumor and lymph node metastasis were markedly reduced. Figure 1 shows that SPARC was overexpressed in tumor stroma in TBLB specimen obtained before treatment.

\section{Discussion}

We have demonstrated that stromal SPARC reactivity is high in patients with squamous cell carcinoma who are

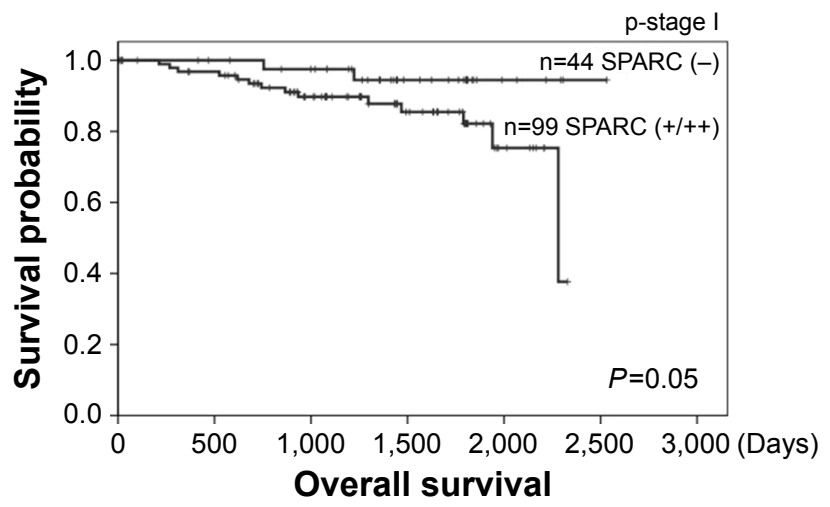

Figure 2 Cumulative Kaplan-Meier survival curves stratified according to SPARC immunostaining of specimens from patients in pathological stage $\mathrm{I}$. Abbreviation: SPARC, secreted protein acidic and rich in cysteine. 
Table 3 Clinicopathological characteristics of NSCLC patients who received chemotherapy

\begin{tabular}{|c|c|}
\hline & Total $(\mathbf{N}=\mathbf{4 3})$ \\
\hline Age, years & $49-80($ mean 70$)$ \\
\hline \multirow[t]{2}{*}{ Gender } & Male $(n=33)$ \\
\hline & Female $(n=10)$ \\
\hline \multirow[t]{2}{*}{$\mathrm{BI}$} & $<400(n=10)$ \\
\hline & $\geq 400(\mathrm{n}=33)$ \\
\hline \multirow[t]{3}{*}{ Histology } & Ad $(n=19)$ \\
\hline & $\mathrm{Sq}(\mathrm{n}=18)$ \\
\hline & Other $(n=6)$ \\
\hline \multirow[t]{3}{*}{ Stage } & IIIA $(n=5)$ \\
\hline & IIIB/IV (n=27) \\
\hline & Post-operative recurrence $(\mathrm{n}=\mathrm{I} \mathrm{I})$ \\
\hline \multirow[t]{4}{*}{ Specimen } & TBB, TBLB $(n=12)$ \\
\hline & CT-guided lung biopsy $(n=3)$ \\
\hline & EBUS-TBNA (LNs) $(n=13)$ \\
\hline & Surgical specimen $(n=15)$ \\
\hline
\end{tabular}

Abbreviations: NSCLC, non-small-cell lung cancer; Bl, Brinkman index; Ad, adenocarcinoma; Sq, squamous cell carcinoma; TBB, transbronchial biopsy; TBLB, transbronchial lung biopsy; CT, computed tomography; EBUS-TBNA, endobronchial ultrasound-guided transbronchial needle aspiration; LNs, lymph nodes.

smokers and correlated with poor prognosis. Strong SPARC stroma reactivity was seen in lung cancer patients who evidenced tumor response to chemotherapy containing nab-paclitaxel. These results suggest that SPARC expression might be involved in tumor progression and response to nab-paclitaxel.

SPARC has an important role in tissue remodeling, angiogenesis, and embryonic development. In normal tissues and bones, SPARC is expressed during remodeling and repair, but not in a stationary state. ${ }^{13,14}$ However, SPARC has been reported to be overexpressed in, and correlated with poor prognosis with, various cancers, such as breast, pancreas, head and neck, bladder, and cervix uteri cancers. ${ }^{10-12,15-17}$ In breast cancer, overexpression of SPARC is associated with microcalcifications and bone metastases. ${ }^{18}$ Another study reported that SPARC was detected in $54.2 \%$ of 253 cases

Table 4 Relationship between stromal SPARC reactivity in biopsy or surgical specimens and tumor response to nab-paclitaxel in NSCLC

\begin{tabular}{llllll}
\hline $\begin{array}{l}\text { Tumor } \\
\text { response }\end{array}$ & \multicolumn{4}{l}{ Stromal SPARC reactivity } & P-value \\
\cline { 2 - 5 } & $(-)$ & $(+)$ & $(++)$ & NE & \\
\hline PR $(n=20)$ & 0 & 2 & 13 & 5 & $0.002^{*}$ \\
SD $(n=13)$ & 2 & 7 & 2 & 2 & $0.02^{* *}$ \\
PD $(n=10)$ & 3 & 2 & 3 & 2 & \\
\hline
\end{tabular}

Notes: *PR vs SD; **PR vs PD evaluable cases only.

Abbreviations: SPARC, secreted protein acidic and rich in cysteine; NSCLC, nonsmall-cell lung cancer; NE, not evaluated; PR, partial response; SD, stable disease; $\mathrm{PD}$, progressive disease. with resected infiltrating ductal carcinoma of the breast. ${ }^{19}$ According to our result, where stromal SPARC reactivity was correlated with vessel invasion, it is speculated to be associated with cancer invasion and metastasis. Because SPARC expression was observed in stromal tissue but not in cancer cells, we assume that SPARC may function as a tumor promoter mediated through a cancer-stromal interaction.

SPARC expression in the stroma, but not in the tumor cells, was correlated with improved survival of pancreatic cancer patients treated with nab-paclitaxel in conjunction with gemcitabine. ${ }^{12}$ Albumin acts as a drug carrier and accumulates in solid tumors due to leaky capillaries combined with an absent or defective lymphatic drainage system. SPARC has an ability to bind albumin, causing albumin accumulation in malignant tissues..$^{20,21}$ This binding ability might be involved in the association between SPARC expression and nab-paclitaxel efficacy. We demonstrated a significant correlation between stromal SPARC reactivity in NSCLC and tumor response to nab-paclitaxel using biopsy or surgical specimens obtained from patients previously treated with chemotherapy. These results suggest that high stromal reactivity of SPARC has the potential to be a predictive factor for nab-paclitaxel efficacy in patients with lung cancer. Transcytosis from vessel to tumor tissue mediated through caveolae is well known to be a method of drug delivery for nab-paclitaxel..$^{22}$ A high level of caveolin-1, a major component of caveolae, in tumor stroma was reported to be associated with improved response to nab-paclitaxel in conjunction with carboplatin and improved survival in NSCLC patients. ${ }^{23}$ Molecules related to drug delivery, such as SPARC and caveolin-1, may therefore be useful as predictive markers for nab-paclitaxel. There are few patients with progressive disease, so further investigation is necessary to increase the number of cases.

A limitation of this proposed assay system is the difficulty in evaluating SPARC expression in tumor stroma in advanced cases due to the small sizes of tissue specimens. Furthermore, aspiration biopsy of lymph node using EBUSTBNA cannot be used for the evaluation because stromal tissue is not contained in lymph nodes. Recently, endobronchial ultrasonography with a guide sheath (EBUS-GS) enables us to perform biopsy of small lesions in the peripheral region. ${ }^{24}$ Using such new technology, biopsy of the primary lesion should be promoted for the evaluation of stroma. nabPaclitaxel demonstrates a higher response rate in patients with squamous cell carcinoma, and in some cases they evidence marked tumor shrinkage as presented in Figure 1. If SPARC is available as a predictive marker in the clinical setting, 
we expect that nab-paclitaxel will occupy the forefront of tailor-made therapy for lung cancer, especially squamous cell carcinoma.

\section{Conclusion}

nab-Paclitaxel demonstrates a higher response rate in patients with squamous cell carcinoma, and in some cases they evidence marked tumor shrinkage as presented in Figure 1. If SPARC is available as a predictive marker in the clinical setting, we expect that nab-paclitaxel will occupy the forefront of tailor-made therapy for lung cancer, especially squamous cell carcinoma.

\section{Acknowledgments}

The authors would like to give heartfelt thanks to Dr Hironori Sadamatsu who contributed to the treatment of patients and collection of biopsy specimens, and Mr Fumihiro Mutoh for technical assistance with the experiments.

\section{Disclosure}

The authors report no conflicts of interest in this work.

\section{References}

1. Lynch TJ, Bell DW, Sordella R, et al. Activating mutations in the epidermal growth factor receptor underlying responsiveness of non-small-cell lung cancer to gefitinib. N Engl J Med. 2004;350(21):2129-2139.

2. Soda M, Choi YL, Enomoto M, et al. Identification of the transforming EML4-ALK fusion gene in non-small-cell lung cancer. Nature. 2007; 448(7153):561-566.

3. Socinski MA, Bondarenko I, Karaseva NA, et al. Weekly nab-paclitaxel in combination with carboplatin versus solvent-based paclitaxel plus carboplatin as first-line therapy in patients with advanced non-smallcell lung cancer: final results of a phase III trial. J Clin Oncol. 2012; 30(17):2055-2062.

4. Guarneri V, Dieci MV, Conte P. Enhancing intracellular taxane delivery: current role and perspectives of nanoparticle albumin-bound paclitaxel in the treatment of advanced breast cancer. Expert Opin Pharmacother. 2012;13(3):395-406.

5. Chen J, Wang M, Xi B, et al. SPARC is a key regulator of proliferation, apoptosis and invasion in human ovarian cancer. PLoS One. 2012; 7(8):e42413.

6. Zhang JL, Chen GW, Liu YC, et al. Secreted protein acidic and rich in cysteine (SPARC) suppresses angiogenesis by down-regulating the expression of VEGF and MMP-7 in gastric cancer. PLoS One. 2012; 7(9):e44618.

7. Gorantla B, Bhoopathi $\mathrm{P}$, Chetty $\mathrm{C}$, et al. Notch signaling regulates tumor-induced angiogenesis in SPARC-overexpressed neuroblastoma. Angiogenesis. 2013;16(1):85-100.

OncoTargets and Therapy

\section{Publish your work in this journal}

OncoTargets and Therapy is an international, peer-reviewed, open access journal focusing on the pathological basis of all cancers, potential targets for therapy and treatment protocols employed to improve the management of cancer patients. The journal also focuses on the impact of management programs and new therapeutic agents and protocols on
8. Kiessling F, Fink C, Hansen M, et al. Magnetic resonance imaging of nude mice with heterotransplanted high-grade squamous cell carcinomas: use of a low-loaded, covalently bound Gd-Hsa conjugate as contrast agent with high tumor affinity. Invest Radiol. 2002;37(4):193-198.

9. Chuang VT, Kragh-Hansen U, Otagiri M. Pharmaceutical strategies utilizing recombinant human serum albumin. Pharm Res. 2002;19(5): 569-577.

10. Jones C, Mackay A, Grigoriadis A, et al. Expression profiling of purified normal human luminal and myoepithelial breast cells: identification of novel prognostic markers for breast cancer. Cancer Res. 2004; 64(9):3037-3045.

11. Nagai MA, Gerhard R, Fregnani JH, et al. Prognostic value of NDRG1 and SPARC protein expression in breast cancer patients. Breast Cancer Res Treat. 2011;126(1):1-14.

12. Von Hoff DD, Ramanathan RK, Borad MJ, et al. Gemcitabine plus nab-paclitaxel is an active regimen in patients with advanced pancreatic cancer: a phase I/II trial. J Clin Oncol. 2011;29(34):4548-4554.

13. Watkins G, Douglas-Jones A, Bryce R, Mansel RE, Jiang WG. Increased levels of SPARC (osteonectin) in human breast cancer tissues and its association with clinical outcomes. Prostaglandins Leukot Essent Fatty Acids. 2005;72(4):267-272.

14. Porter PL, Sage EH, Lane TF, Funk SE, Gown AM. Distribution of SPARC in normal and neoplastic human tissue. J Histochem Cytochem. 1995;43(8):791-800.

15. Chin D, Boyle GM, Williams RM, et al. Novel markers for poor prognosis in head and neck cancer. Int J Cancer. 2005;113(5):789-797.

16. Yamanaka M, Kanda K, Li NC, et al. Analysis of the gene expression of SPARC and its prognostic value for bladder cancer. J Urol. 2001; 166(6):2495-2499.

17. Sova P, Feng Q, Geiss G, et al. Discovery of novel methylation biomarkers in cervical carcinoma by global demethylation and microarray analysis. Cancer Epidemiol Biomarkers Prev. 2006;15(1):114-123.

18. Bellahcène A, Castronovo V. Increased expression of osteonectin and osteopontin, two bone matrix proteins, in human breast cancer. $\mathrm{Am} \mathrm{J}$ Pathol. 1995;146(1):95-100.

19. Kim YW, Park YK, Lee J, Ko SW, Yang MH. Expression of osteopontin and osteonectin in breast cancer. J Korean Med Sci. 1998; 13(6):652-657.

20. Kratz F. Albumin as a drug carrier: design of prodrugs, drug conjugates and nanoparticles. J Control Release. 2008;132(3):171-183.

21. Schnitzer JE, Oh P. Albondin-mediated capillary permeability to albumin. Differential role of receptors in endothelial transcytosis and endocytosis of native and modified albumins. J Biol Chem. 1994; 269(8):6072-6082.

22. Razani B, Woodman SE, Lisanti MP. Caveolae: from cell biology to animal physiology. Pharmacol Rev. 2002;54(3):431-467.

23. Bertino EM, Williams TM, Nana-Sinkam SP, et al. Stromal Caveolin-1 is associated with response and survival in a phase II trial of nabpaclitaxel with carboplatin for advanced NSCLC patients. Clin Lung Cancer. 2015;16(6):466-474.

24. Kurimoto N, Miyazawa T, Okimasa S, et al. Endobronchial ultrasonography using a guide sheath increases the ability to diagnose peripheral pulmonary lesions endoscopically. Chest. 2004;126(3):959-965. patient perspectives such as quality of life, adherence and satisfaction The manuscript management system is completely online and includes a very quick and fair peer-review system, which is all easy to use. Visit http://www.dovepress.com/testimonials.php to read real quotes from published authors. 